\title{
LEVELS OF HYPOXIA INDUCIBLE FACTOR-1 $\alpha$ (HIF-1 $\alpha$ ) AND INTERCELLULAR ADHESION MOLECULE-1 (ICAM-1) AFTER INTRAVITREAL BEVACIZUMAB IN PROLIFERATIVE DIABETIC RETINOPATHY
}

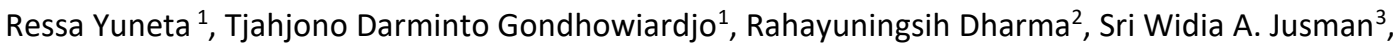 \\ Joedo Prihartono ${ }^{4}$, Andi Arus Victor ${ }^{1}$ \\ ${ }^{1}$ Department of Ophthalmology, Faculty of Medicine, Universitas Indonesia \\ Cipto Mangunkusumo Hospital, Indonesia \\ ${ }^{2}$ Department of Clinical Pathology, Faculty of Medicine, Universitas Indonesia \\ ${ }^{3}$ Department of Biochemistry, Faculty of Medicine, Universitas Indonesia \\ ${ }^{4}$ Department of Community Health, Faculty of Medicine, Universitas Indonesia
}

\begin{abstract}
Introduction: to assess the levels of Hypoxia-inducible factor-1 $\alpha$ (HIF-1 $\alpha)$ and intercellular adhesion molecule1 (ICAM-1) in vitreous of proliferative diabetic retinopathy patients which were given intravitreal bevacizumab (IVB), as well as its relation to the central macular thickness (CMT) measured prior to vitrectomy.

Methods: thirty-two eyes were randomized into two groups, one that received an IVB injection at 1-2 weeks previtrectomy and the control group which did not receive any injection. Measurement of HIF-1 $\alpha$ and ICAM-1 was conducted using enzyme-linked immunosorbent assay (ELISA). The CMT were measured at the initial visit, prior to vitrectomy, and at follow up time $(2,4$, and 12 weeks postoperatively) using Stratus OCT.

Results: The mean levels of HIF-1 $\alpha$ vitreous ( $\mathrm{ng} / \mathrm{mg}$ protein) in the control group and IVB respectively 0.020 $(0.006 ; 0.077)$ and $0.029(0.016 ; 0.21)$. Vitreous levels of ICAM- $1(\mathrm{ng} / \mathrm{mL})$ in control group and IVB group were $20.10(3.41 ; 40.16)$ and $23.33(0.63 ; 68.5)$. The mean levels of HIF-1 $\alpha$ and ICAM-1 vitreous obtained did not differ significantly between the two groups.
\end{abstract}

Conclusion: The levels of HIF-1 $\alpha$ and ICAM-1 in PDR patients do not decrease after one injection of intravitreal Bevacizumab 1-2 weeks prior to vitrectomy. The concentration of vitreous HIF-1 $\alpha$ and ICAM-1 are not directly related to the CMT.

Keywords: proliferative diabetic retinopathy, HIF-1 $\alpha$, ICAM-1, intravitreal bevacizumab

Cite This Article: YUNETA, Ressa et al. LEVELS OF HYPOXIA INDUCIBLE FACTOR-1 $\alpha$ (HIF-1 $\alpha$ ) AND INTERCELLULAR

ADHESION MOLECULE-1 (ICAM-1) AFTER INTRAVITREAL BEVACIZUMAB IN PROLIFERATIVE DIABETIC RETINOPATHY.

International Journal of Retina, [S.I.], v. 2, n. 1, feb. 2019. ISSN 2614-8536. Available at:

<https://www.ijretina.com/index.php/ijretina/article/view/60>.

${ }^{*}$ Correspondence to:

Andi Arus Victor,

Department of Ophthalmology,

Universitas Indonesia,

arvimadao@yahoo.com

\section{INTRODUCTION}

Diabetic retinopathy $(\mathrm{DR})$ is a complication of diabetes mellitus (DM) on the retina caused by uncontrolled high blood glucose levels in long term. Proliferative diabetic retinopathy (PDR) is the advanced form of DR characterized by the formation of new blood vessels in the retina which increases the risk of visual loss. ${ }^{1,2}$ Diabetic retinopathy is the most commonly found retinal vascular disorder in the Vitreoretina policlinic at
Cipto Mangunkusumo Hospital. ${ }^{3}$ In 2004 2009, there were 3988 DR visits and $38.3 \%$ of them were PDR. The percentage of PDR visits was increased to $47.9 \%$ in 2010-2012. ${ }^{4}$

Damage to the structure of the retina as a result of long term hyperglycemia is the main pathogenesis of DR. PDR begins from retinal ischemia due to microvascular occlusion and retinal capillary nonperfusion 
It results in increased production of Vascular Endothelial Growth Factor (VEGF), which stimulates the formation of neovascularization. The new vessels are fragile and can lead to the buildup of lipoproteins and bleeding in the retina and vitreous. 5,6

Research with therapy focusing on biomolecular activity is expected in order to prevent the pathological retinal response to hypoxia. ${ }^{3,7}$ Recent studies have shown that elevated HIF-1 $\alpha$ and ICAM-1 levels affect the DR progression in PDR patients. ${ }^{3,8-13} \mathrm{HIF}-1 \alpha$ is a protein that plays a major role as a transcription factor in VEGF regulation, in which its accumulation was induced by retinal hypoxia. ${ }^{3}, 10,13,14$ VEGF will increase retinal vascular permeability, microvascular occlusion, teleangiectasia, microaneurysms and retinal ischemia. Retinal ischemia leads to hypoxia that will stimulate the formation of HIF$1 \alpha$, which in turn triggers more VEGF. ${ }^{15,}{ }^{16}$ ICAM- 1 is an adhesion molecule that plays a role in inflammatory mechanisms of blood vessel's wall. Vascular Endothelial Growth Factor is known to corelate with ICAM-1 in the neovascularization process. ${ }^{17-19}$

\section{METHODS}

This study is a prospective, post-test only, open-labeled randomized clinical trial. The subjects of this study were 32 eyes of 32 PDR patients which were evaluated from January to November 2016 at Vitreoretina policlinic of Cipto Mangunkusumo Hospital. Subjects were divided into two groups, each group consisted of 16 subjects. The control group was treated with vitrectomy only, whereas bevacizumab group received IVB injection 1-2 weeks prior to vitrectomy. Inclusion criterias were DM patients aged more than 18 years, with vitreomacular traction or nonclearing vitreous haemmorhage, who are willing to participate in the study, and with signed informed consent. Patients with a previous history of vitrectomy surgery, intravitreal anti-VEGF or laser photocoagulation, and patients without central macular thickness (CMT) measurement before vitrectomy were excluded from this study.

A volume of $0.5-1 \mathrm{~mL}$ vitreous sample was retrieved with $1 \mathrm{~mL}$ syringe connected to vitrectomy cutter before running intravenous fluids during vitrectomy. The concentrations of HIF- $1 \alpha$ and ICAM- 1 from the sample were measured in Biochemistry and Clinical Pathology Laboratory at Cipto Mangunkusumo Hospital. Using sandwich-type enzyme-linked immunosorbent assay (ELISA). The HIF-1 $\alpha$ level was recorded in each $1 \mathrm{mg}$ of protein ( $\mathrm{ng} / \mathrm{mg}$ protein). ELISA kit for HIF-1 $\alpha$ (Elabscience) and ELISA kits for ICAM-1 ((R\&D Systems) was performed based on the recommendations of the manufacturer. Stratus OCT (Carl Zeiss Meditec, Dublin, CA) was used to measure CMT. All subjects were measured for their CMT and visual acuity (VA) at $2^{\text {nd }}, 4^{\text {th }}$, and $12^{\text {th }}$ week postoperatively. SPSS version 17.0 was used for analysis, based on the intention to treat analysis.

This clinical study was approved by the Ethical Clearance Committee of Faculty of Medicine, Universitas Indonesia based on the Declaration of Helsinki, with ethical clearance number of 229/UN2.F1/ETHICS/2015.

\section{RESULTS}

Table 1: Distribution of demographic data

\begin{tabular}{|c|c|c|c|}
\hline \multirow{2}{*}{ Variable } & \multicolumn{2}{|c|}{ Group } & \multirow{2}{*}{$\mathbf{P}$} \\
\hline & Control & IVB & \\
\hline Age & $46.5 \pm 10.2$ & $50.62 \pm 6.25$ & $0.180^{\mathrm{a}}$ \\
\hline \multicolumn{4}{|l|}{ Gender } \\
\hline Male & 6 & 3 & \multirow{2}{*}{$0.433^{b}$} \\
\hline Female & 10 & 13 & \\
\hline Duration of DM (year) & $6.50(1 ; 20)$ & $7(1 ; 20)$ & $0.746^{c}$ \\
\hline Total cholesterol (mg/dL) & $242.8 \pm 56.8$ & $226.6 \pm 67.5$ & $0.469^{\mathrm{a}}$ \\
\hline Systolic blood pressure $(\mathrm{mmHg})$ & $147.5 \pm 19.6$ & $141.31 \pm 22.7$ & $0.403^{\mathrm{a}}$ \\
\hline Diastolic blood pressure $(\mathrm{mmHg})$ & $83.7 \pm 12.3$ & $76.1 \pm 10.1$ & $0.067^{\mathrm{a}}$ \\
\hline $\mathrm{HbA} 1 \mathrm{c}(\%)$ & $8.96 \pm 2.1$ & $9.43 \pm 1,40$ & $0.450^{\mathrm{a}}$ \\
\hline Mean initial CMT $(\mu \mathrm{m})$ & $507(116 ; 1673)$ & $741(233 ; 1471)$ & $0.522^{c}$ \\
\hline Mean CMT prior to vitrectomy $(\mu \mathrm{m})$ & $507(177 ; 1673)$ & $600(193 ; 1363)$ & $0.797^{c}$ \\
\hline Mean initial visual acuity (logMAR) & $1.8 \pm 0.3$ & $1.9 \pm 0.1$ & $0.248^{\mathrm{a}}$ \\
\hline $\begin{array}{l}\text { Mean visual acuity prior to vitrectomy } \\
\text { (logMAR) }\end{array}$ & $1.8 \pm 0.4$ & $1.9 \pm 0.3$ & $0.540^{\mathrm{a}}$ \\
\hline
\end{tabular}

The level of HbA1c, duration of diabetes, and initial CMT were higher in the IVB group, but these differences were not statistically significant $(p>0.05)$ 


\section{*Mann Whitney test}

\begin{tabular}{lccc}
\hline \multirow{2}{*}{ Variable } & \multicolumn{2}{c}{ Groups } & \multirow{2}{*}{ P } \\
\cline { 2 - 3 } & \multicolumn{1}{c}{ Control } & IVB & \\
\hline $\begin{array}{l}\text { Level of HIF-1 } \alpha \\
\text { (ng/mg protein) }\end{array}$ & $0.020(0.006 ; 0.077)$ & $0.029(0.016 ; 0.21)$ & $0.172^{*}$ \\
Level of ICAM-1 $(\mathrm{ng} / \mathrm{mL})$ & $20.10(3.41 ; 40.16)$ & $23.33(0.63 ; 68.5)$ & $0.777^{*}$ \\
\hline
\end{tabular}

The levels of vitreous HIF- $1 \alpha$ and ICAM- 1 in the IVB group are higher than the control group, but not statistically significant $(p>0.05)$.

Table 3: Mean CMT of each group at baseline, prior to vitrectomy and at $2^{\text {nd }}, 4^{\text {th }}$, and $12^{\text {th }}$ weeks postoperative

\begin{tabular}{lccc}
\hline \multirow{2}{*}{$\mathbf{C M T}(\boldsymbol{\mu m})$} & \multicolumn{2}{c}{ Groups } & P \\
\cline { 2 - 3 } & Control & IVB & $0.434^{*}$ \\
\hline Initial & $507(116 ; 1673)$ & $741(233 ; 1471)$ & \\
Prior to vitrectomy & $507(177 ; 1673)$ & $600(193 ; 1363)$ & \\
$2^{\text {nd }}$ week postoperative & $267(120 ; 693)$ & $328(230 ; 545)$ & \\
$4^{\text {th }}$ week postoperative & $274(129 ; 724)$ & $320(193 ; 1275)$ & \\
$1^{\text {th }}$ week postoperative & $275.5(169 ; 1473)$ & $323(201 ; 575)$ & \\
\hline
\end{tabular}

*Anova 2 Way with General Linear Model

There is no statistically significant difference in CMT measurement between two groups at every measurement time $(p>0.05)$.

Table 4: Mean CMT at pre and post IVB injection in the IVB group

\begin{tabular}{|c|c|c|c|}
\hline \multirow{2}{*}{ IVB Group } & \multicolumn{2}{|c|}{ Time of measurement } & \multirow[b]{2}{*}{$\mathbf{P}$} \\
\hline & Pre IVB injection & Post IVB injection & \\
\hline $\mathrm{CMT}(\mu \mathrm{m})$ & $741(233 ; 1471)$ & $600(193 ; 1363)$ & $<0.002^{*}$ \\
\hline
\end{tabular}

*Wilcoxon test

The decrease of the CMT between pre-IVB injection (baseline) and post IVB injection (pre-vitrectomy) was statistically significant $(p<0.002)$.
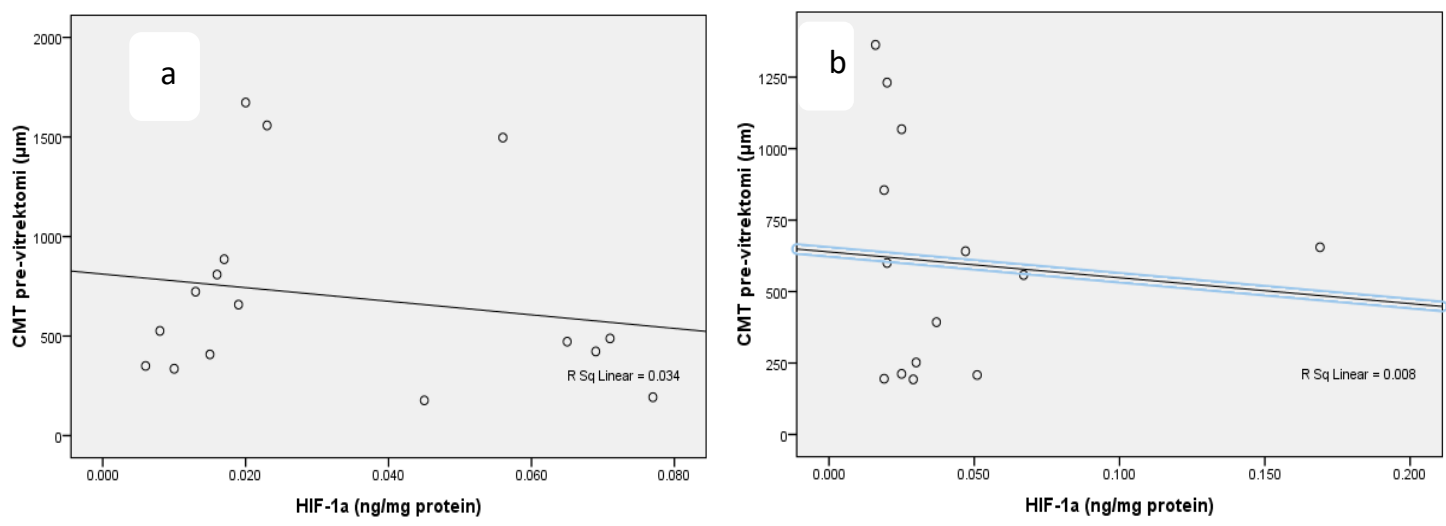

Figure 1: Correlation between HIF-1 $\alpha$ concentration with CMT prior to vitrectomy in $(a)$ control group $($ Spearman; $r=-$ 0.038 dan $p=0.888$ ) and (b) IVB group (Spearman; $r=-0.280$ dan $p=0.332$ ). 

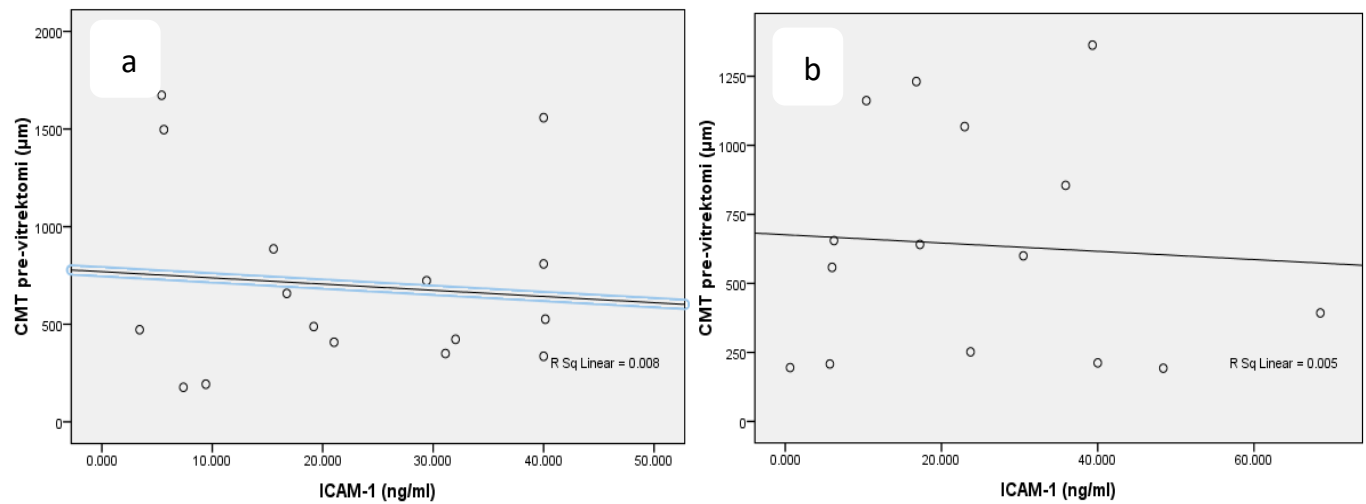

Figure 2: Correlation between ICAM-1 concentration with CMT prior to vitrectomy in (a) control group (Spearman; $r=-$ 0.041 dan $p=0.879$ ) and (b) IVB group (Spearman; $r=-0.004$ dan $p=0.990)$.

Scattered diagrams at figure 1 and 2 above shows that there were no correlations between HIF- $1 \alpha$ and ICAM-1 on CMT value prior to vitrectomy in both groups. The subject of this research consists of PDR patients with vitreomacular traction on most subjects, so this might affect the value of CMT in this study. Statistical tests were conducted in 26 subjects ( 14 control group and 12 IVB group) who had a complete VA data at every follow-ups.

Table 5: Visual acuity in both groups at baseline, prior to vitrectomy and at 2,4 , and 12 weeks post-operation

\begin{tabular}{|c|c|c|c|}
\hline \multirow{2}{*}{$\begin{array}{l}\text { Visual acuity } \\
\text { (logMar) } \pm \text { SD }\end{array}$} & \multicolumn{2}{|c|}{ Groups } & \multirow{2}{*}{$\mathbf{P}$} \\
\hline & Control & IVB & \\
\hline Initial & $1.81 \pm 0.36$ & $1.93 \pm 0.13$ & $0.013^{*}$ \\
\hline $\begin{array}{l}\text { Prior to } \\
\text { vitrectomy }\end{array}$ & $1.83 \pm 0.36$ & $1.90 \pm 0.26$ & \\
\hline $\begin{array}{l}2^{\text {nd }} \quad \text { week } \\
\text { postoperative }\end{array}$ & $1.99 \pm 0.31$ & $1.93 \pm 0.26$ & \\
\hline $\begin{array}{l}4^{\text {th }} \quad \text { week } \\
\text { postoperative }\end{array}$ & $1.69 \pm 0.65$ & $1.98 \pm 0.08$ & \\
\hline $\begin{array}{l}12^{\text {th }} \quad \text { week } \\
\text { postoperative }\end{array}$ & $1.61 \pm 0.74$ & $2.00 \pm 0.00$ & \\
\hline
\end{tabular}

*Anova 2 way with General Linear Model

Only 26 subjects had a complete data of VA at all followups period and were included for the VA analysis, 14 from the control group and 12 from the IVB group. Postoperative VA in the IVB group was worse than in the control group at all measured time frames. These differences in VA between the two groups were statistically significant.

Post-operative complications appeared to be almost equal in proportion between the two groups. Postoperative vitreous hemorrhage in IVB group was found in subjects without silicone oil. Hyphema occured in the control group with poor blood pressure and blood sugar control (HbA1c: $11 \mathrm{mg} / \mathrm{dl})$.
Table 4.6 Postoperative complications

\begin{tabular}{lccc}
\hline \multirow{2}{*}{ Complications } & \multicolumn{2}{c}{ Groups $(\mathbf{\Sigma})$} & \multirow{2}{*}{ Total } \\
\cline { 2 - 3 } & Control & IVB & \\
\hline $\begin{array}{l}\text { Postoperative } \\
\text { vitreous }\end{array}$ & - & 3 & 3 \\
hemmorhage & & & $(9.38 \%)$ \\
Hyphema & 2 & - & 2 \\
$\begin{array}{l}\text { Retinal } \\
\text { redetachment }\end{array}$ & 1 & 1 & $\begin{array}{c}(6.25 \%) \\
2 \\
\text { Cataract }\end{array}$ \\
$\begin{array}{lccc}(6.25 \%) \\
\text { Glaucoma }\end{array}$ & 2 & 2 & 4 \\
& 3 & - & $\begin{array}{c}(12.5 \%) \\
3 \\
(9.38 \%)\end{array}$ \\
\hline
\end{tabular}

\section{DISCUSSION}

This study shows that the difference between the levels of HIF- $1 \alpha$ and ICAM-1 in both groups is not statistically significant ( $p>0.05$ ). These results might be influenced by several factors such as the baseline levels of HIF- $1 \alpha$ and ICAM-1, inadequate decreased of VEGF level in the IVB group, or a change in inflammatory mediators after IVB injection. Decreased levels of HIF-1 $\alpha$ and ICAM- 1 could not be seen if the baseline levels were higher in the IVB group. However in this study, the measurement of HIF- $1 \alpha$ and ICAM-1 before vitrectomy could not be obtained.

Anti-VEGF binds to VEGF molecules, hence, preventing the VEGF to bind to its receptors. Bevacizumab works by holding on to all isoforms of VEGF-A. It has a longer halflife time and higher molecular weight than ranibizumab. ${ }^{20,}$ 21 Victor et al ${ }^{22}$ reported that PDR patients who had an IVB injection prior to vitrectomy had twice as low VEGF levels than the group that did not receive IVB.

Han et $\mathrm{al}^{23}$ studied the effects of IVB injection 6 days prior to vitrectomy to the level of HIF- $1 \alpha$ through immunohistochemical examination of the fibrovascular membrane obtained during vitrectomy. Expression of HIF$1 \alpha$ in DR group that had been given IVB injection was found to be lower than that of the control group. The 
subjects in the study were PDR with vitreous hemmorhage, traction, or macular edema. However, some patients in the study group also received laser photocoagulation before vitrectomy. Han et $\mathrm{al}^{32}$ also discovered that laser photocoagulation prior to vitrectomy, prevents further ischemia and decreases the HIF- $1 \alpha$ concentration.

Inadequate reduction of VEGF level in the IVB group could also affect the HIF- $1 \alpha$ result in the IVB group. Victor et $\mathrm{al}^{22}$ report that the lowest levels of VEGF found in the group that received a combination of laser photocoagulation and IVB injection. The levels of VEGF in the combination therapy were found to be 5 times lower compared to the control group. The similar HIF-1 $\alpha$ levels between the case and the control group could be caused by the severe PDR subjects who require laser photocoagulation and IVB combination therapy, to achieve a significant ischemia inhibition effect to reduce levels of HIF- $1 \alpha$.

Another factor that can contribute to the rising HIF- $1 \alpha$ concentration in this study is the change in inflammatory mediators after the IVB injection. An increased inflammatory mediator is a response from VEGF blockade, but the details are not completely understood. Some researchers reported inflammatory mediators change after IVB injection. ${ }^{24,}{ }^{25}$ Forooghian et al ${ }^{25}$ reported a significant increase in inflammatory mediators such as IL8 and TGF- $\beta 2$ in the aqueous humor of PDR patients at 10 days after IVB administration. Stilla et $a^{26}$ report the effects of inflammatory mediators on HIF-1 $\alpha$. In inflammation, Ang-II, thrombin, TGF- $\beta 2$ (Transforming Growth Factor- $\beta 2$ ), IL-1 $\beta$ (Interleukin-1 $\beta$ ), TNF- $\alpha$ (Tumor Necrosis Factor- $\alpha$ ), NF- $\mathrm{kB}$, and other factors contribute to the accumulation of HIF- $1 \alpha$. Increased TGF- $\beta 2$ is expected to affect the expression of HIF-1 $\alpha$ in inflammatory processes. ${ }^{26}$

ICAM-1 can be induced by other inflammatory mediators such as IL- 1 and TNF- $\alpha$, which can be induced by TGF- $\beta .{ }^{27}$ Yan et al ${ }^{28}$ reported the post-injection effect of ranibizumab on levels of ICAM-1 for before and after 7 days. The study reported that the level of ICAM- 1 in the group injected with ranibizumab one week prior to vitrectomy was higher than the control group. In the group who received ranibizumab injection for more than 1 week before vitrectomy, the level of ICAM-1 was lower than the control group. These results demonstrate that administration of intravitreal anti-VEGF can increase the ICAM-1 concentration in the initial period. However, our study uses bevacizumab which is a heavier Anti VEGF molecule, and persist for a longer periode in the vitreous when compared to ranibizumab. Hence, the inflammation effect after IVB is expected to last longer than that of ranibizumab.

HIF- $1 \alpha$ affects the progression of macular edema in PDR. There was no correlation between the levels of HIF-

Published by : INAVRS https://www.inavrs.org/ | International Journal of Retina https://ijretina.com 2019; 2; 1;
$1 \alpha$ and ICAM-1 on CMT prior to vitrectomy. CMT is affected by inflammation and also by vitreomacular traction of the fibrovascular membrane. The traction located at the optic disc area or along the vascular arcades will cause antero-posterior traction in the macular area. ${ }^{29}$

The mean baseline VA in this study was $1.81 \pm 0.36$ in the control group and $1.93 \pm 0.13$ in the IVB group. The poor baseline VA in the IVB group might have certain effects on the also poor postoperative VA. This finding was similar to a study by Kaiser et $a^{30}$ that reported the patient with poor initial VA $(\log M A R>1)$ have a settled VA within 1 year after vitrectomy. Abdelhakim et $a^{31}$ also found that VA in the subject with IVB injection 7 days prior to vitrectomy was not improved, even in patients with VA more than $\log M A R=1$ or slightly better. The decrease in macular thickness happened in most of the subjects. This is consistent with a study by Arevalo ${ }^{32}$ that found that intravitreal bevacizumab injections may have a beneficial effect on macular thickness and VA, even though CMT improvement is not always followed by VA improvement. ${ }^{33}$

Recurrent vitreous hemorrhage occurred in three patients from IVB group without silicone oil tamponade. Yeung et $\mathrm{al}^{34}$ reported that intraocular tamponade is more effective than IVB injection to prevent recurrent postoperative vitreous hemmorhage. Silicone oil has tamponade and compression effect on the blood vessels of the retina. Retinal redetachments occurred in two subjects, 1 subject in each group. It happened due to fibrovascular reproliferation or intraoperative atrophicretina-related retinal tears. ${ }^{35}$

Hyphema was found in two subjects with glaucoma. It occurred in the control group who had poor blood sugar and blood pressure control.

This study is the first study that assesses both the vitreous levels of HIF- $1 \alpha$ and ICAM- 1 in PDR patients who received IVB injection. Baseline measurement of the HIF$1 \alpha$ and ICAM- 1 levels are not possible is found to be limitations of this study. Greater number of subjects and examinations of other proinflammatory cytokines that may affect the levels of HIF- $1 \alpha$ and ICAM- 1 such as VEGF, interleukin, TNF- $\alpha$, and TGF- $\beta$ can be done in relation to this study.

\section{CONCLUSION}

The levels of HIF- $1 \alpha$ and ICAM- 1 in PDR patients do not decrease after one injection of intravitreal Bevacizumab 12 weeks prior to vitrectomy. The concentration of vitreous HIF- $1 \alpha$ and ICAM- 1 are not directly related to the CMT. 


\section{ETHICS AND CONSENT TO PARTICIPATE}

Written informed consent was obtained from the patient. The ethical clearance approval (No:

229/UN2.F1/ETIK/2015) was obtained from the Health

Research Ethics Committee of Faculty of Medicine,

Universitas Indonesia and a copy of it was submitted to the editor of this journal.

\section{CONFLICT OF INTERESTS}

All authors hereby declare no conflicts of interest.

\section{ACKNOWLEDGEMENT}

Authors would like to express their gratitude to all parties who have aided the making of this manuscript.

\section{REFERENCES}

1. Retinal vascular disease : diabetic retinopathy. San Fransisco: American academy of ophthalmology 2014-2015.

2. Kanski J, Bowling B. Diabetic retinopathy in: Kanski J, Bowling B, editors. Clinical Ophthalmology: A Systematic Approach. 7 ed. United Kingdom: Elsevier; 2011.

3. Arjamaa $O$, Nikinmaa M. Oxygen-dependent diseases in the retina: role of hypoxia-inducible factors. Experimental eye research. 2006;83(3):473-83.

4. Sasongko MB, Widyaputri F, Agni AN, Wardhana FS, Kotha S, Gupta $P$, et al. Prevalence of Diabetic Retinopathy and Blindness in Indonesian Adults With Type 2 Diabetes. American journal of ophthalmology. 2017;181:79-87.

5. Fletcher E CN. Vaughan \& Asbury's General Ophthalmology. 17th ed ed. McGraw Hill ed. London 2007.

6. Besirli CG, Johnson MW. Proliferative diabetic retinopathy. Mayo Clinic proceedings. 2009;84(12):1054-

7. Girgis $\mathrm{CM}$, Cheng $\mathrm{K}$, Scott $\mathrm{CH}$, Gunton JE. Novel links between HIFs, type 2 diabetes, and metabolic syndrome. Trends in endocrinology and metabolism: TEM. 2012;23(8):372-80.

8. Adamiec-Mroczek J, Oficjalska-Mlynczak J. Assessment of selected adhesion molecule and proinflammatory cytokine levels in the vitreous body of patients with type 2 diabetes--role of the inflammatoryimmune process in the pathogenesis of proliferative diabetic retinopathy. Graefe's archive for clinical and experimental ophthalmology $=$ Albrecht von Graefes Archiv fur klinische und experimentelle Ophthalmologie. 2008;246(12):1665-70.

9. Adamiec-Mroczek JO-M, Misiuk-Hojło M. Proliferative diabetic retinopathy-The influence of diabetes control on the activation of the intraocular molecule system. . Diabetes research and clinical practice 2008;. 2008(84):46-50.
10. Antonetti DK, R. Gardner, T. . Mechanism of disease diabetic retinopathy : Review. N Engl J Med 2012(366):1227-39.

11. Khalfaoui T, Lizard G, Beltaief O, Colin D, Ben Hamida J, Errais K, et al. Immunohistochemical analysis of cellular adhesion molecules (ICAM-1, VCAM-1) and VEGF in fibrovascular membranes of patients with proliferative diabetic retinopathy: preliminary study. Pathologiebiologie. 2009;57(7-8):513-7.

12. Limb GA, Webster $L$, Soomro $H$, Janikoun $S$, Shilling J. Platelet expression of tumour necrosis factoralpha (TNF-alpha), TNF receptors and intercellular adhesion molecule-1 (ICAM-1) in patients with proliferative diabetic retinopathy. Clinical and experimental immunology. 1999;118(2):213-8.

13. Zhang $X$, Bao S, Hambly BD, Gillies MC. Vascular endothelial growth factor-A: a multifunctional molecular player in diabetic retinopathy. The international journal of biochemistry \& cell biology. 2009;41(12):2368-71.

14. Okur V, Cetin O, Cetin E, Tepeli E, Bulgu Y, Yildirim C. HIF1A as a major vascular endothelial growth factor regulator: do its polymorphisms have an association with age-related macular degeneration? Clinical \& experimental ophthalmology. 2015;43(1):47-53.

15. Tolentino MJ, Miller JW, Gragoudas ES, Jakobiec FA, Flynn E, Chatzistefanou K, et al. Intravitreous injections of vascular endothelial growth factor produce retinal ischemia and microangiopathy in an adult primate. Ophthalmology. 1996;103(11):1820-8.

16. Tolentino MJ, McLeod DS, Taomoto M, Otsuji T, Adamis AP, Lutty GA. Pathologic features of vascular endothelial growth factor-induced retinopathy in the nonhuman primate. American journal of ophthalmology. 2002;133(3):373-85.

17. Kima I, Moona S-O, Kima SH, Kimb HJ, Koha YS, Koh GY. VEGF Stimulates Expression of ICAM-1, VCAM-1 and E-Selectin through Nuclear Factor-K B Activation in Endothelial Cells. The American Society for Biochemistry and Molecular Biology. 2000.

18. Radisavljevic Z, Avraham H, Avraham S. Vascular endothelial growth factor up-regulates ICAM-1 expression via the phosphatidylinositol $3 \mathrm{OH}-$ kinase/AKT/Nitric oxide pathway and modulates migration of brain microvascular endothelial cells. The Journal of biological chemistry. 2000;275(27):20770-4.

19. Lu M, Perez VL, Ma N, Miyamoto K, Peng HB, Liao JK, et al. VEGF increases retinal vascular ICAM-1 expression in vivo. Investigative ophthalmology \& visual science. 1999;40(8):1808-12.

20. Simo R, Hernandez C. Intravitreous anti-VEGF for diabetic retinopathy: hopes and fears for a new therapeutic strategy. Diabetologia. 2008;51(9):1574-80.

21. Salam A, Mathew $R$, Sivaprasad S. Treatment of proliferative diabetic retinopathy with anti-VEGF agents. Acta ophthalmologica. 2011;89(5):405-11. 
22. Victor AA, Gondhowiardjo TD, Waspadji S, Wanandi SI, Bachtiar A, Suyatna FD, et al. Effect of laser photocoagulation and bevacizumab intravitreal in proliferative diabetic retinopathy: review on biomarkers of oxidative stress. Med J Indones. 2014;23(2):79-86.

23. Han XX, Guo CM, Li Y, Hui YN. Effects of bevacizumab on the neovascular membrane of proliferative diabetic retinopathy: reduction of endothelial cells and expressions of VEGF and HIF-1 $\alpha$. Molecular vision. 2012;18:1-9.

24. Jeon S, Lee WK, Jung Y. Changes in the intraocular cytokine levels after intravitreal bevacizumab in uveitic macular edema. Ocular immunology and inflammation. 2012;20(5):360-4.

25. Forooghian F, Kertes PJ, Eng KT, Agrón E, Chew EY. Alterations in the intraocular cytokine milieu after intravitreal bevacizumab. Investigative ophthalmology $\&$ visual science. 2010;51(5):2388-92.

26. Frede S, Berchner-Pfannschmidt U, Fandrey J. Regulation of hypoxia-inducible factors during inflammation. Methods in enzymology. 2007;435:405-19.

27. Elmarakby AA, Sullivan JC. Relationship between oxidative stress and inflammatory cytokines in diabetic nephropathy. Cardiovascular therapeutics. 2012;30(1):4959.

28. Yan Y, Zhu L, Hong L, Deng J, Song Y, Chen X. The impact of ranibizumab on the level of intercellular adhesion molecule type 1 in the vitreous of eyes with proliferative diabetic retinopathy. Acta ophthalmologica. 2016;94(4):358-64.

29. Bhagat N, Grigorian RA, Tutela A, Zarbin MA. Diabetic macular edema: pathogenesis and treatment. Survey of ophthalmology. 2009;54(1):1-32.
30. Kaiser RS, Maguire MG, Grunwald JE, Lieb D, Jani $B$, Brucker AJ, et al. One-year outcomes of panretinal photocoagulation in proliferative diabetic retinopathy. American journal of ophthalmology. 2000;129(2):178-85.

31. Abdelhakim MA, Macky TA, Mansour KA, Mortada HA. Bevacizumab (Avastin) as an adjunct to vitrectomy in the management of severe proliferative diabetic retinopathy: a prospective case series. Ophthalmic research. 2011:45(1):23-30.

32. Arevalo JF, Garcia-Amaris RA. Intravitreal Bevacizumab for Diabetic Retinopathy. Current Diabetes Reviews. 2009;5:39-46.

33. Browning DJ, Glassman AR, Aiello LP, Beck RW, Brown DM, Fong DS, et al. Relationship between optical coherence tomography-measured central retinal thickness and visual acuity in diabetic macular edema. Ophthalmology. 2007;114(3):525-36.

34. Yeung L, Liu L, Wu WC, Kuo YH, Chao AN, Chen $\mathrm{KJ}$, et al. Reducing the incidence of early postoperative vitreous haemorrhage by preoperative intravitreal bevacizumab in vitrectomy for diabetic tractional retinal detachment. Acta ophthalmologica. 2010;88(6):635-40.

35. Sima P, Zoran T. Long-term results of vitreous surgery for proliferative diabetic retinopathy. Documenta ophthalmologica Advances in ophthalmology. 1994;87(3):223-32.

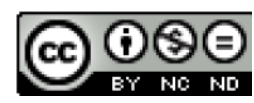

This work licensed under Creative Commons Attributio 